Oktober 2018 Volume 2 No 1

\title{
STRATEGI PEMASARAN KELAPA SAWIT MELALUI PENDEKATAN ANALISIS STRUCTURE CONDUCT AND PERFORMANCE (SCP) DI KABUPATEN SIMALUNGUN
}

\section{PALM OIL MARKETING STRATEGY THROUGH STRUCTURE CONDUCT AND PERFORMANCE ANALYSIS (SCP) APPROACH IN SIMALUNGUN REGENCY}

\author{
Ira Apriyanti ${ }^{1}$, Juwita Ramadhani ${ }^{1}$ \\ 1) Departement of Agribusiness, Universitas Muhammadiyah Sumatera Utara \\ Jl. Kapt. Mukhtar Basri No. 3A Medan \\ *corresponding author: iraapriyanti@umsu.ac.id
}

\begin{abstract}
The purpose of this study was to determine the marketing strategy of palm oil using a structure, behavior and marketing performance approach to: (1) Analyze the market structure of the palm oil industry in Tanah Jawa District, Simalungun Regency. (2) Analyzing the marketing function so that it is known the behavior of the palm oil market in Tanah Jawa District, Simalungun Regency. (3) Analyzing the margin and farmer share so that the performance of the palm oil industry is known in the Tanah Jawa District of Simalungun Regency. (4) Analysis of the relationship between the structure, behavior and performance of the palm oil industry in Tanah Jawa District, Simalungun Regency. The analytical method used in this research is marketing channel analysis and market structure analysis which is seen from market concentration and market entry barriers. Analysis of market behavior seen from the marketing function, namely the exchange function, physical function and facility functions. Analysis of market performance seen from the farmer share and marketing margin.

Based on the results of research conducted, the market structure of the palm oil industry in Tanah Jawa District, Simalungun District is an imperfect competition market that is oligopolistic, with an average market concentration of 83 percent. This means that the market structure in Kecamatan Tanah Jawa is grouped in strict oligopoly and the average barriers to market entry are 9 percent, so there is no obstacle to enter the market in Tanah Jawa District, Simalungun Regency. Market behavior in the palm oil industry in Tanah Jawa District, Simalungun District can be seen from the pricing strategy and product strategy. The price strategy is carried out by collusion between market participants, namely making the highest production costs in consideration of sales prices. Product strategy is done by classifying products based on size, price and product quality. There are several marketing institutions, namely farmers, small agents, large agents, factories. Each marketing agency performs marketing functions. In marketing activities the existence of capital ties by farmers with small agents and large agents causes contractual ties.

Market performance analysis (Market Performance) of palm oil in Tanah Java District, Simalungun District shows that there are 3 marketing channels with different margins. The highest total margin is found in marketing channel III, which is 34.06 percent, the more marketing institutions involved, the higher the marketing margin and the lower farmer share. The most efficient marketing channel is the marketing channel I (farmer-factory).
\end{abstract}

Keywords: Marketing Strategy, Farmer Share, Margin, Market Performance, Market Structure.

\section{A. PENDAHULUAN}

Tanah Jawa Kabupaten Simalungun merupakan daerah perkebunan kelapa sawit milik rakyat yang memiliki luasan areal perkebunan kelapa sawit 1025,91 Ha (BPS, 2015). Dengan luasan tersebut permasalahan yang sering hadir pada pemasaran kelapa sawit Bentuk pasar monopoli atau oligopoli dianggap merugikan petani. Kerugian tersebut dapat dilihat dari share bagian petani yang rendah. Bukti share tersebut dinilai dari perbedaan antara harga petani dan pabrik mencapai Rp. 400/kg. Permasalahan kedua terletak pada keterbatasan modal. Petani memiliki rmodal yang rendah sehingga fungsi pertukaran yang hanya dilakukan.
Fluktuasi harga produk pertanian juga menjadi permasalahan utama dalam sistem pemasaran. Petani sering mengalami kerugian akibat fluktuasi harga. Fluktuasi harga terjadi karena produksi kelapa sawit hanya terkonsentrasi pada daerah-daerah tertentu, pola produksi yang tidak sesuai, fasilitas yang tidak memadai, hingga panjangnya rantai pemasaran produk pertanian (Sinaga et al., 2014).

Berdasarkan uraian diatas, maka diperlukan adanya pendekatan Structure, Conduct, Performance $(S C P)$. Pendekatan SCP ini mampu menjelaskan bagaimanalangkah yang semestinya diambil, karena dengan mengetahui struktur, perilaku, dankinerja pasar maka dapat diketahui strategi kebijakan 
pemasaran yang paling tepat untukdilakukan. Struktur, perilaku, dan kinerja industri merupakan variabel yang saling berhubungansatu sama lain dan ketiga variabel ini akan saling mempengaruhi. Oleh karena itupenelitian dengan pendekatan SCP ini penting untuk dilakukan.

\section{B. METODE PENELITIAN}

Penelitian dilakukan di sentra perkebunan kelapa sawit di Kabupaten Simalungun, yaitu Kecamatan Tanah Jawasebagai fokus penelitian.Jenis data yang digunakan adalah data primer dan data sekunder yang bersifat time series melalui pendekatan SCP (Structure Conduct Performance) yaitu: pengumpulan data produksi petani dan agen besar, pada harga yang diterima produsen.

Analisis yang digunakan dalam penelitian ini adalah analisis saluran pemasaran, analisis struktur pasar (konsentrasi pasar dan hambatan keluar masuk pasar), analisis perilaku pasar, dan analisis kinerja pasar (farmer share dan marjin pemasaran).

Analisis struktur pasar dapat dilihat dari :

\section{a. Konsentrasi Pasar}

Konsentrasi pasar dapat dihitung dengan CR4 (four Firm Concentration Rasio) yang merupakan metode analisis dengan tujuan untuk melihat output yang mampu dihasilkan oleh 4 bandar di Kecamatan Tanah Jawa. Hirschey (2009) menjelaskan nilai CR4 $\geq 0,8$ menunjukkan industri terkonsentrasi kuat. Untuk nilai CR4 antara $0.5<\mathrm{CR} 8<0,8$ menunjukkan pasar terkonsentrasi sedang, dan nilai $\mathrm{CR} 4 \leq 0,5$ menunjukkan pasar terkonsentrasi lemah. Rumus konsentrasi pasar, yaitu :

$$
\mathbf{C R 4}=\frac{\mathbf{S 1}+\mathbf{S 2}+\mathbf{S 3}+\mathbf{S 4}}{\mathbf{S T}} \ldots \ldots \ldots(1.1)
$$

Keterangan :

$$
\text { CR4 = Konsentrasi rasio }
$$

S1 = Volume penjualan kelapa sawit oleh bandar 1 (ton/tahun)

$\mathrm{Sn} \quad=$ Volume penjualan kelapa sawit

oleh bandar ke-n (ton/tahun)

ST = Total Penjualan seluruh kelapa sawit oleh bandar di Kecamatan Tanah Jawa(ton/tahun)

\section{b. Hambatan Keluar Masuk Pasar}

Hambatan keluar masuk pasar dapat dihitung dengan Minimum Efficiency Scale (MES), yaitu perhitungan penjualan Kelapa sawit yang dilakukan oleh bandar terhadap total kelapa sawit di Kecamatan Tanah Jawa, Kabupaten Simalungun. Hambatan masuk dapat dihitung dengan rumus: $\begin{aligned} \boldsymbol{M E S}= & \frac{\text { Penjualankelapasawitolhpengumpulkampung }}{\text { JmlkelapasawitdiTanahJawa }} \\ \text { (1.2) } & \text { Jika.... }\end{aligned}$ persen maka diindikasikan bahwa pemasaran komoditi kelapa sawit terdapat hambatan masuk (Jaya, 2001).

\section{Analisis Perilaku Pasar}

Perilaku pasar merupakan aktivitas-aktivitas yang terjadi di pasar. Perilaku pasar berkaitan erat dengan struktur pasar dan kinerja pasar. Dengan adanya struktur pasar dan perilaku pasar akan membentuk kinerja pasar. Kohls dan Downey (1972) menjelaskan 3 fungsi pemasaran dalam perilaku pasar, yaitu fungsi pertukaran, fisik dan fasilitas (penyediaan sarana).

\section{a. Fungsi Pertukaran}

Fungsi pertukaran adalah kegiatan yang menyangkut pengalihan hak kepemilikan barang dari satu pihak ke pihak lain. Dalam fungsi pertukaran terdiri dari penjualan dan pembelian.

\section{b. Fungsi Fisik}

Fungsi fisik adalah kegiatan yang melibatkan penanganan, gerakan, dan perubahan fisik produk. Terdapat 3 fungsi di dalam fungsi fisik, yaitu pengangkutan, penyimpanan, dan pemrosesan.

\section{c. Fungsi Fasilitas}

Fungsi fasilitas atau penyediaan sarana adalah kegiatan yang memper-lancar fungsi pertukaran dan fisik dalam pemasaran, meliputi sortasi dan grading, informasi harga, penanganan risiko, dan pembiayaan.

\section{Analisis Kinerja Pasar}

Salah satu indiktor yang dapat menunjukkan kinerja pasar adalah keuntungan yang diperoleh dalam suatu industri. Analisis kinerja pasar dapat dilihat dengan menghitung marjin pemasaran dan farmer share. Panjangnya saluran pemasaran yang ada belum tentu menunjukkan bahwa kinerja pemasaran tersebut tidak efisien. Jika rantai pemasaran panjang dan mampu meningkatkan kepuasan konsumen maka dapat dikatakan bahwa sistem pemasaran tersebut efisien.

\section{a. Analisis Penerimaan (revenue)}

Penerimaan total yaitu jumlah seluruh penerimaan perusahaan dari hasil penjualan sejumlah produk (barang yang dihasilkan). Cara untuk menghitung penerimaan total dapat dilakukan dengan mengalikan jumlah produk dengan harga jual produk per taandan buah segar penelitian Natalia, A.J. (2016). Jika dirumuskan sebagai berikut: 


\section{STRATEGI PEMASARAN KELAPA SAWIT MELALUI PENDEKATAN ANALISIS}

Keterangan:

$$
\mathrm{TR}=\mathrm{Y} \text { x Py........................ (1.3) }
$$

$\mathrm{TR}=$ Penerimaan total perusahaan $(\mathrm{Rp})$

$\mathrm{Y}=$ Jumlah produk yang dihasilkan $(\mathrm{Kg})$

$\mathrm{Py}=$ Harga jual tandan buah segar (Rp)

\section{b. Analisis Keuntungan}

Komponen biaya total terdiri dari biaya variabel (biaya tidak tetap) dan biaya tetap. Biaya variabel adalah biaya yang secara total berubah secara proporsional dengan perubahan aktivitas, dengan kata lain biaya variabel adalah biaya yang besarnya dipengaruhi oleh jumlah produksi yang dihasilkan, akan tetapi biaya variabel per unit sifatnya konstan. Adapun rumus keuntungan sebagai berikut;

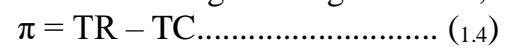

Keterangan:

$$
\pi \quad=\text { Keuntungan petani (Rp) }
$$$$
\text { TR =Penerimaan total (Total }
$$

Revenue) (Rp)

$$
\text { TC =Biaya total (total cost) }
$$

(Rp)

Rumus biaya tenaga kerja yaitu;

$$
\frac{P X Q}{O}
$$

Keterangan:

$$
\begin{array}{ll}
\mathrm{P} & =\text { Harga upah }(\mathrm{Rp}) \\
\mathrm{Q} & \text { =Jumlah produksi }(\mathrm{kg}) \\
\mathrm{O} & \text { =Jumlah upah tenaga kerja }
\end{array}
$$

(orang)

Rumus Total biaya yaitu;

$$
\mathrm{TC}
$$

$=\mathrm{TFC}+\mathrm{TVC}$

Keterangan:

TC :Biaya total (Total Cost) (Rp)

Cost) (Rp)

TFC :Biaya Tetap total (Total Fixed

TVC :Biaya Variabel total (Total

Variabel Cost) (Rp)

\section{c. Marjin Pemasaran}

Marjin dapat menunjukkan nilai tambah dari petani hingga sampai di tangan konsumen. Analisis marjin ini dapat digunakan untuk menganalisis sistem pemasaran dari perspektif makro (pemasaran produk dari petani hingga konsumen). Adapun rumus dari marjin pemasaran dapat dilihat sebagai berikut:

$$
\begin{aligned}
& \mathbf{M T}=\mathbf{P r}- \\
& \text { Pf... } \\
& \text { Keterangan : } \\
& \text { MT = Marjin Total } \\
& \operatorname{Pr} \quad=\text { Harga Kelapa sawit di tingkat } \\
& \text { konsumen akhir(Rp/kg) }
\end{aligned}
$$

$$
\mathrm{Pf}=\text { Harga Kelapa sawit di tingkat petani }(\mathrm{Rp} / \mathrm{kg})
$$

\section{d. Farmer share}

Farmer share merupakan persentase harga yang diterima oleh petani dengan harga yang dibayarkan konsumen. Beberapa hal yang mempengaruhi farmer share, di antaranya tingkat pemrosesan, biaya transportasi, jumlah produk, dan keawetan produk. Farmer share berhubungan negatif dengan marjin pemasaran. Bila marjin pemasaran semakin tinggi, maka bagian yang diterima oleh petani semakin rendah. Farmer share dapat dihitung dengan rumus:

$$
\begin{aligned}
& F S=\frac{P_{f}}{P_{r}} \times \\
& 100 \text { persen. }
\end{aligned}
$$

Keterangan :

$$
\begin{aligned}
& \mathrm{FS} \quad=\text { Persentase yang diterima Petani } \\
& \mathrm{Pr} \quad=\text { Harga kelapa sawit di tingkat } \\
& \text { konsumen }(\mathrm{Rp} / \mathrm{kg}) \\
& \mathrm{Pf} \quad=\text { Harga kelapa sawit di tingkat } \\
& \text { petani }(\mathrm{Rp} / \mathrm{kg}) .
\end{aligned}
$$

\section{HASIL dan PEMBAHASAN \\ Konsentrasi Pasar}

Konsentrasi rasio empat perusahaan terbesar $\left(\mathrm{CR}_{4}\right)$ menggambarkan perwakilan dari empat agen besar yang ada di Kecamatan Tanah Jawa sehingga melalui pendekatan $\mathrm{CR}_{4}$ akan digunakan untuk melihat persentase total output empat agen perusahaan terbesar terhadap total output keseluruh industri. Dalam industri kelapa sawit yang ada di Kecamatan Tanah Jawa diperoleh nilai rata-rata $\mathrm{CR}_{4}$ dari bulan januari-desember 2015 adalah 83 persen. Hal ini menunjukkan bahwa empat agen besar memiliki persaingan dalam pasar oligopoli. Penelitian sitorus (2012) pada industri kakao, rata-rata konsentrasi pasar sebesar 67,41 persen. Dengan besaran seperti ini maka sifat oligopoli ini dikelompokkan dalam oligopoli ketat atau quasicompetitive model, yaitu dimana masing-masing pelaku industri melakukan kolusi atau adanya kerjasama.

Menurut Jaya (2001) pasar oligopoli dapat dibedakan atas dua jenis, yaitu oligopoli longgar dan oligopoli ketat. Pembedaan ini didasarkan pada besarnya nilai konsentrasi pasar. Jika konsentrasi pasar berkisar 40-60 persen maka dikelompokkan menjadi oligopoli longgar, sedangkan konsentrasi pasar yang berkisar 60-100 persen digolongkan ke dalam oligopoli ketat, maka dapat disimpulkan industri kelapa sawit yang ada di Kecamatan Tanah Jawa merupakan pasar oligopoli ketat. Dalam ekonomi industri kelapa sawit sistem oligopoli ini 
Ira Apriyanti, Juwita Ramadhani

memang dianggap sebagai oligopi ketat. Dari hasil penelitian rata-rata $\mathrm{CR}_{4}$ dari bulan januari - desember 2015 hingga mencapai 83 persen, maka pasar di Kecamatan Tanah Jawa terkonsentrasi kuat atau ketat.

\section{Hambatan Keluar Masuk Pasar}

Masuk dan keluarnya suatu industri dapat menggambarkan persaingan yang terjadi dalam industri tersebut sehingga hambatan untuk masuk pasar dapat terdeteksi. Melalui pendekatan Minimum Effisiency Scale (MES) dapat diketahui besarnya persentase hambatan untuk masuk pasar. Nilai MES yang diperoleh dengan cara membagi nilai output terbesar agen dengan total output dalam industri. Sepanjang bulan januari - desember, rata-rata nilai MES industri kelapa sawit di Kecamatan Tanah Jawa adalah sebesar 9 persen. Penelitian Ramlii (2004), tentang komoditas pertanian menyatakan nilai MES yang didapat 9 persen sehingga tidak ada hambatan masuk pasar untuk agen kecil. Semakin tinggi nilai MES, maka hambatan untuk memasuki pasar akan semakin sulit pula. Menurut nilai MES yang lebih dari 10 persen menggambarkan hambatan masuk pasar yang tinggi pada industri.

Menurut Comanor dan Wilson (1967), MES yang lebih besar dari 10 persen menggambarkan hambatan masuk yang tinggi pada suatu industri. Hal ini disebabkan karena melonjaknya nilai output industri kelapa sawit. Tidak jauh berbeda dengan pengaruh output pada nilai $\mathrm{CR}_{4}$, peningkatan nilai output ini dapat disebabkan karena peningkatan nilai input. Dari hasil penelitian MES industri di Kecamatan Tanah Jawa adalah sebesar 9 persen maka pemasaran komoditi kelapa sawit tidak ada hambatan masuk pasar.

\section{Analisis Perilaku Pasar}

Perilaku pasar merupakan aktivitas-aktivitas yang teradi di pasar dan erat kaitannya dengan struktur dan kinerja pasar. Dengan adanya struktur pasar dan perilaku pasar akan membentuk kunerja pasar. Analisis perilaku pasar dilakukan untuk mengetahui bagaimana pasar dijalankan serta menganalisis proses pemasaran yang dilakukan oleh lembaga pemasaran. Hal tersebut diketahui dengan melakukan pengamatan pada pemasaran kelapa sawit, sistem penentuan dan pembayaran harga, serta kerja sama antar pelaku pemasaran. Perilaku pasar menggambarkan tingkah laku dan penerapan strategi yang dilakukan perusahaan untuk menguasai pangsa pasar sebesar mungkin. Analisis saluran pemasaran merupakan perangkat yang saling bergantung sama lainnya. Kohls dan Downey (1972) menjelaskan 3 fungsi pemasaran, yaitu fungsi pertukaran, fungsi fisik dan fungsi fasilitas. Dari hasil penelitian tersebut, maka fungsi pemasaran dalam perilaku pasar di Kecamatan Tanah Jawa adalah Fungsi pertukaran, fungsi fisik dan fungsi fasilitas.

\section{Fungsi-Fungsi Pemasaran Pada Setiap Lembaga Pemasaran}

Pada sistem pemasaran kelapa sawit di Kecamatan Tanah Jawa terdiri atas beberapa lembaga pemasaran yang terlibat. Masing-masing lembaga pemasaran tentunya menjalankan fungsi-fungsi pemasaran dengan tujuan untuk memperlancar proses penjualan produk. Fungsi pemasaran yang dijalankan terdiri dari fungsi pertukaran, fungsi fisik dan fungsi fasilitas. Setiap lembaga pemasaran dapat menjalankan lebih dari satu fungsi sesuai dengan peranan masing- masing dalam keberlangsungan aktivitas pemasaran.

Fungsi pertukaran merupakan proses perpindahan hak milik atas suatu barang dari produsen kepada konsumen. Fungsi ini terdiri atas fungsi penjualan dan fungsi pembelian. Fungsi penjualan merupakan pelaksanaan dari hal-hal yang berkaitan dengan cara penjualan. Sementara fungsi pembelian merupakan penentuan jenis produk yang akan dibeli oleh agen. Kegiatan utama yang dijalankan oleh agen besar dan agen kecil adalah menentukan jenis, kuantitas dan mutu dari barang yang dijual.

Fungsi fisik merupakan kegiatan yang berhubungan langsung dengan produk sehingga menimbulkan kegunaan tempat, kegunaan bentuk dan kegunaan waktu. Fungsi fisik terdiri dari beberapa aktivitas seperti penyimpanan, pengolahan, dan pengangkutan. Fungsi penyimpanan dilakukan untuk mengatur keseimbangan suplai produk sepanjang tahun. Pada sistem pemasaran kelapa sawit ini pelaksanaan fungsi pengangkutan dan sortasi memiliki peranan dalam membantu petani meningkatkan kualitas produk yang dijual. Hal ini dikarenakan permintaan dari pihak konsumen adalah kelapa sawit dalam bentuk tandan buah segar (TBS) siap olah, karena dengan pemanenan dan pengolahan serta penanganan yang baik akan meningkatkan kualitas dari kelapa sawit yang dijual. Prinsip TBS segera mungkin diterima pabrik pengolahan.

Sementara itu, yang menjadi bagian dari kegiatan pada fungsi fasilitas meliputi fungsi standarisasi, fungsi pembiayaan, fungsi penanggungan resiko, dan fungsi informasi pasar. Kegiatan yang termasuk dalam fungsi fasilitas merupakan kegiatan yang dilakukan dengan tujuan untuk memperlancar penyaluran dan pertukaran antara produsen dan konsumen. Lembaga-lembaga pemasaran kelapa sawit di Kecamatan Tanah Jawa 


\section{STRATEGI PEMASARAN KELAPA SAWIT MELALUI PENDEKATAN ANALISIS}

pada umumnya menjalankan fungsi-fungsi pemasaran.

\section{Fungsi Pemasaran di Tingkat Petani}

Pada pelaksanaan penelitian ini, penjualan kelapa sawit yang dilakukan oleh petani dibagi ke dalam tiga bagian, pertama penjualan TBS milik petani langsung ke pabrik pengolahan, kedua penjualan TBS milik petani dijual melalui agen besar kemudian diangkut ke pabrik pengolahan dan ketiga penjualan TBS milik petani melalui agen kecil kemudian yang dijual ke agen besar dengan tujuan akhir adalah pabrik pengolahan.

Pada saluran I sampai saluran III ini termasuk fungsi pemasaran fungsi pertukaran, karena dalam saluran tersebut petani melakukan penjualan tandan buah segar sebanyak 100 persen. Sedangkan pada fungsi fisik berada pada saluran I dan saluran II yang menggunakan transportasi atau pengangkutan sebanyak 58 persen. Dan 100 persen fungsi fasilitas berada pada setiap saluran I sampai saluran III dikarenakan mengeluarkan pembiayaan untuk produksi seperti uang panen dan lain sebagainya. Pada fase ini, fungsi penyimpanan tidak berlaku karena seluruh petani kelapa sawit tidak melakukan penyimpanan hasil panennya. Seluruh hasil panen berupa tandan buah segar (TBS) siap olah dijual langsung ke pabrik melalui agen kecil atau agen besar.

Petani melakukan peminjaman modal dari agen kecil maupun agen besar dan ada juga peminjaman modal dari bank. Jumlah petani yang meminjam ke agen kecil dan agen besar sebanyak 50 persen dan peminjaman ke bank sebanyak 50 persen. Petani yang melakukan peminjaman dari pihak agen kecil dan agen besar akan memiliki kontrak dan petani tersebut tidak bisa pindah untuk memasarkan kelapa sawit ke agen lain maupun beralih ke pabrik sebelum hutang petani dilunaskan.

\section{Fungsi Pemasaran di Tingkat Agen Kecil}

Di kecamatan Tanah Jawa, agen Kecil kelapa sawit umumnya menjalankan ketiga fungsi pemasaran yaitu fungsi pertukaran, fungsi fisik dan fungsi fasilitas. Pembelian kelapa sawit dari petani yang dilakukan oleh agen kecil dan dijual keagen besar dan pabrik dan itu disebut juga dengan fungsi pertukaran sebanyak 100 persen. Penetapan harga baik harga jual maupun beli ditingkat agen kecil biasanya disesuaikan terlebih dahulu dengan informasi harga yang diperoleh dari pihak pabrik maupun agen besar disebut fungsi fasilitas sebanyak 100 persen. Dan 100 persen agen kecil ini mempunyai gudang yang terletak di samping rumahnya dan 100 persen mengeluarkan pembiayaan setiap hari ini juga disebut fungsi fasilitas. 50 persen agen kecil meminjamkan modal dari Bank dan 25 persen agen kecil meminjam modal dari agen besar. Ada pun yang termasuk fungsi fisik yaitu berupa kegiatan, 100 persen agen kecil melakukan transportasi sendiri, Fungsi pengangkutan dilakukan oleh agen kecil untuk mengangkut hasil kelapa sawit berupa tandan buah segar (TBS) siap olah milik petani. Kegiatan pengangkutan dilakukan dengan menggunakan alat pengangkutan berupa mobil truk yang mampu menampung kelapa sawit berupa tandan buah segar (TBS) sekitar 8-10 ton. Penggunaan sarana pengangkutan dengan kapasitas tersebut mengharuskan agen kecil berulang kali melakukan pengangkutan. Hal ini tentunya akan mempengaruhi tingkat biaya pemasaran yang dikeluarkan untuk pengangkutan.

Setiap 2 kali sebulan atau disebut 2 kali pemanenan, Agen kecil biasanya mengambil hasil panen kelapa sawit berupa tandan buah segar (TBS) atau biasanya dari pihak petani yang menghubungi agen kecil langsung sesuai dengan kesepakatan waktu. Pada fase ini, fungsi penyimpanan berlaku hanya untuk beberapa jam saja, karena masih menunggu seluruh petani selesai melakukan pemanenan dihari yang sama dan juga memenuhi truk yang belum penuh dengan tandan buah segar.

\section{Fungsi Pemasaran di Tingkat Agen besar}

Agen besar merupakan pihak yang memfasilitasi aktivitas pemasaran antara petani pembudidaya kelapa sawit dengan pihak pabrik yang berada di Kecamatan Tanah Jawa Kabupaten Simalungun Provinsi Sumatera Utara. Agen besar melakukan fungsi pertukaran dan fungsi fisik. 100 persen agen besar melakukan Pada fungsi pertukaran, karena melakukan pembelian tanda buah segar dari petani dan agen kecil dan penjualan tanda buah segar ke pabrik . 100 persen agen besar melakukan pada fungsi fasilitas, karena melakukan kegiatan sortasi, informasi harga dari pabrik, penanganan resiko dan pembiayaan. Dan 100 persen agen besar melakukan peminjaman modal dari Bank.

Fungsi fisik yang dilakukan oleh pihak agen besar adalah mengangkut hasil panen kelapa sawit berupa tandan buah segar (TBS) siap olah dari lokasi gudang ke pihak pabrik PTPN IV Bandar Pasir Mandoge. Dalam menjalankan kegiatan pengangkutan ini, agen besar menggunakan truk dengan muatan per truk sebesar 20 ton. Agen besar tidak melakukan fungsi penyimpanan, karena hasil kelapa sawit tandan buah segar (TBS) langsung dikirim langsung kepada pihak pabrik dengan tujuan ke berbagai daerah. 


\section{Pabrik Pengolahan Kelapa Sawit}

Pabrik Pengolahan Kelapa Sawit merupakan lembaga pemasaran akhir dalam penelitian ini. Pabrik yang menjadi responden dalam penelitian ini merupakan pabrik yang berada diwilayah Kecamatan Tanah Jawa yaitu PKS PTPN IV Bandar Pasir Mandoge.

Fungsi yang berlaku di pabrik ini yaitu fungsi pertukaran, fungsi fisik dan fungsi fasilitas. Pada fungsi pertukaran, pihak pabrik 100 persen melakukan pembelian melalui petani, agen kecil dan agen besar yang berada di wilayah Kecamatan Tanah Jawa dan sekitarnya. Selanjutnya pihak pabrik juga 100 persen melakukan fungsi penjualan dengan hasil olahan kelapa sawit berupa CPO, dan produk-produk lain selanjutnya akan di ekspor ke luar negeri atau diolah lebih lanjut menjadi berbagai produk seperti minyak makan, margarin dan lain-lain didalam negeri.

Pada pelaksanaan fungsi fisik, pihak pabrik hanya melakukan fungsi pengolahanya itu pembahan hasil kelapa sawit bempa TBS menjadi CPO. Dalam pelaksanaan fungsi fisik, pihak pabrik PTPN IV Bandar Pasir Mandoge tetap melakukan fungsi lainnya seperti penyortiran dan penyimpanan.

\section{Hubungan Struktur dan Kinerja}

Untuk melihat hubungan antara struktur dengan kinerja maka digunakan analisis struktur perilakukinerja, analisis struktur conduct and performance $(S C P)$ melihat bagaimana struktur dan kinerja pasar, dimana struktur pasar adalah karakteristik dan komposisi pasar dan industri dalam suatu perekonomian. Sedangkan kinerja pasar mengacu pada tingkat keberhasilan pasar dalam memberikan manfaat kepada konsumen, misalnya dengan memberikan harga yang rendah. Paradigma structur conduct and performance (SCP) berpendapat bahwa penguasaan pasar yang tinggi cenderung menghasilkan kinerja pasar yang buruk, yaitu konsumen harus membayar harga yang sangat tinggi. Pendekatan SCP mengatakan bahwa struktur akan mempengaruhi profitabilitas secara positif. Struktur pasar dianalisis dengan menggunakan CR4 yang menunjukan bahwa industri kelapa sawit termasuk pasar oligopoli ketat dan marjin pemasaran tinggi.

\section{Analisis Kinerja Pasar}

Kinerja pasar adalah suatu keadaan sebagai akibat dari struktur dan perilaku pasar dalam kenyataan sehari-hari yang ditunjukan dengan harga, biaya, dan volume produksi yang memberikan penilaian baik atau tidaknya suatu sistem pemasaran
(Dahl dan Hammond 1977). Analisis kinerja pasar dapat dilihat dari marjin pemasaran dan farmer share.

\section{Analisis Marjin Pemasaran}

Penentuan tingkat efisiensi suatu sistem pemasaran dapat dilakukan melalui pendekatan análisis marjin pemasaran. Marjin pemasaran adalah penjumlahan dari seluruh biaya pemasaran yang dikeluarkan oleh lembaga pemasaran dan besarnya keuntungan yang diambil dalam aktivitas penyaluran komoditas dari lembaga pemasaran yang satu ke lembaga pemasaran lainnya. Marjin pemasaran yang diperhitungkan dalam penelitian ini berdasarkan pada pola saluran pemasaran yang terbentuk dalam aktivitas pemasaran TBS kelapa sawit di Kecamatan Tanah Jawa. Dalam penelitian ini, marjin pemasaran dapat dilihat disetiap saluran pemasaran.

\section{Marjin Pemasran}

Marjin pemasaran adalah selisih antara harga yang diterima petani dengan harga yang dibayar oleh agen. Marjin untuk setiap saluran pemasran tandan buah segar (TBS) dapat dilihat pada Tabel 1,2,3 dan 4.

Pada saluran pemasaran I petani langsung menjual tanda buah segar (TBS) ke pabrik, artinya tidak melalui lembaga perantara dalam memasarkan hasilnya. Oleh karena itu, harga yang diterima petani sebesar Rp. 1.403, total biaya sebesar Rp. 961,dengan marjin 68,39 persen, keuntungan petani dalam saluran pemasaran I sebesar Rp. 433 dengan marjin 31,61 persen.

Tabel 1. Marjin Pemasaran Pada Saluran I

\begin{tabular}{ccc}
\hline Uraian & $\begin{array}{c}\text { Price Spread } \\
\mathrm{Rp} / \mathrm{Kg}\end{array}$ & $\begin{array}{c}\text { Share Margin } \\
\%\end{array}$ \\
\hline Harga Jual produsen & 1.403 & \\
Total Biaya & 961 & 68,39 \\
Keuntungan petani & 433 & 31,61 \\
Jumlah & 2.797 & 100 \\
Marjin & & 0 \\
\hline
\end{tabular}

Sumber:Analisis data Primer

Pada saluran pemasaran II petani langsung menjual ke agen besar, dan rata-rata harga yang diterima petani sebesar Rp. 1.172 per kg, dan rata-rata total biaya yang di keluarkan petani sebanyak Rp. 821 per $\mathrm{kg}$, dengan marjin 70,05 persen, dengan keuntungan petani sebesar Rp. 351 per kg dengan marjin sebesar 29,95 persen. Dan pembelian tanda buah segar oleh agen besar adalah Rp. 1.172 per kg dengan marjin 83,53 dan rata-rata biaya sebesar 


\section{STRATEGI PEMASARAN KELAPA SAWIT MELALUI PENDEKATAN ANALISIS}

Rp.129 per kg dengan marjin 9,19 persen dan pendapatan agen besar sebanyak Rp. 102 per kg dengan marjin 7,27 persen. Pada saluran II ini marjin sebanyak Rp. 231 dengan marjin 16,46.

Tabel 2. Marjin pemasaran pada saluran II

\begin{tabular}{ccc}
\hline Uraian & $\begin{array}{c}\text { Price } \\
\text { Spread } \\
\text { Rp/Kg }\end{array}$ & $\begin{array}{c}\text { Share } \\
\text { Margin }\end{array}$ \\
& 1.172 & \\
\hline Harga Jual petani & 821 & 70,05 \\
Total Biaya & 351 & 29,95 \\
Keuntungan petani & & 100 \\
Jumlah & 1.172 & 83,53 \\
Harga Beli & 129 & 9,19 \\
Total Biaya & 102 & 7,27 \\
Pendapatan Agen & 1.403 & 100 \\
Besar & & 100 \\
Harga Pabrik & 231 & 16,46 \\
Jumlah & &
\end{tabular}

Sumber: Analisis data Primer

Marjin Pada Saluran Pemasaran III dapat dilihat pada Tabel 15. Dapat diketahui bahwa harga jual petani adalah Rp.925 per kg. Rata-rata Biaya yang dikeluarkan petani sebesar Rp.681 dengan marjin 73,79 persen. Pendapatan petani sebesar Rp.236 per $\mathrm{kg}$ dengan marjin adalah 26,21 persen. Harga beli agen kecil adalah sebesar Rp. 925 dengan marjin 78,78 persen dan biaya keseluruhan sebesar Rp.193 per kg dengan marjin 16,11 persen. Dan pendapatan sebesar Rp. 67 per kg dengan marjin 5,11 persen. Selisih harga pada saluran pemasaran III ini yaitu Rp. 478 dengan total marjin sebesar 34,06.

Tabel.3. Marjin Pemasaran Pada Saluran III

\begin{tabular}{ccc}
\hline Uraian & $\begin{array}{c}\text { Price } \\
\text { Spread } \\
\mathrm{Rp} / \mathrm{Kg}\end{array}$ & $\begin{array}{c}\text { Share } \\
\text { Margin } \\
\%\end{array}$ \\
\hline Harga Jual petani & 925 & \\
Total Biaya & 681 & 73,79 \\
Keuntungan petani & 236 & 26,21 \\
Jumlah & & $100 \%$ \\
Harga Beli & 925 & 78,78 \\
Total Biaya & 193 & 16,11 \\
Pendapatan Agen Kecil & 67 & 5,11 \\
Harga Jual Agen Kecil & 1.172 &
\end{tabular}

Jumlah

100

$\begin{array}{ccc}\begin{array}{c}\text { Harga yang diterima agen } \\ \text { besar }\end{array} & 1.403 & \\ \begin{array}{l}\text { Marjin Agen kecil-petani } \\ \text { Marjin Agen Besar-agen } \\ \text { kecil }\end{array} & 247 & 21,07 \\ \quad 231 & 16,46 \\ \text { Total Marjin } & 478 & 34,06\end{array}$

Sumber: Analisis data Primer

Dari pernyataan analisis data primer diatas, marjin pemasaran saluran I mempunyai 0, saluran II mempunyai marjin sebesar 16,46 persen, sedangkan pada saluran III marjin sebesar 36,04 persen, Marjin yang paling rendah karena saluran lembaga pemasarannya pendek yaitu berada pada saluran I (petani - pabrik), dan marjin yang paling tinggi berada pada saluran III karena lemaga salurannya panjang (petani - agen kecil - agen besar - pabrik) Semakin tinggi marjin pemasaran maka semakin rendah pula farmer share nya. Dan semakin rendah marjin yang didapat, maka saluran tersebut akan menjadi efisien, Saluran yang efisien yaitu saluran pemasaran I.

\section{Farmer share}

Farmer's share adalah perbandingan tingkat harga yang diterima oleh petani dengan harga yang dibayarkan oleh konsumen akhir. Farmer's share merupakan konsep balas jasa atas kegiatan usahatani. Berdasarkan hasil penelitian, besarnya farmer's share petani kelapa sawit di Kecamatan Tanah Jawa berbeda untuk masing-masing saluran pemasaran. Semakin tinggi farmer's share maka semakin rendah marjin pemasaran, Sinaga (2014).

Tabel 4 menunjukkan farmer's share tertinggi terdapat pada saluran pemasaran I (petani - pabrik) yaitu sebesar 100 persen dengan harga jual ditingkat petani dan pabrik sama yaitu Rp. 1.403,-- sedangkan farmer's share terendah terdapat pada saluran III (petani - Agen kecil - agen besar - pabrik) yaitu sebesar 65,94 persen. Perbedaan farmer share yang terjadi pada setiap saluran pemasaran dikarenakan adanya perbedaan harga yang diterima setiap lembaga pemasaran, jumlah lembaga pemasaran yang terlibat serta fungsi-fungsi yang dilakukan sehingga meningkatkan harga di tingkat konsumen.

Tabel 4. Analisis Farmer Share

\begin{tabular}{cccc}
\hline $\begin{array}{c}\text { Saluran } \\
\text { pemasaran }\end{array}$ & $\begin{array}{c}\text { Harga di } \\
\text { tingkat } \\
\text { petani(Rp/kg) }\end{array}$ & $\begin{array}{c}\text { Harga di } \\
\text { tingkat } \\
\text { Konsumen } \\
(\mathrm{Rp} / \mathrm{kg})\end{array}$ & $\begin{array}{c}\text { Farmers } \\
\text { share } \\
(\%)\end{array}$ \\
I & 1.403 & 1.403 & 100 \\
II & 1.172 & 1.403 & 83,53
\end{tabular}


Ira Apriyanti, Juwita Ramadhani

$\frac{\text { III }}{\text { Sumber: Analisis Data Primer }}$

\section{KESIMPULAN dan SARAN \\ Kesimpulan}

Hasil penelitian yang dilakukan pada industri kelapa sawit di Kecamatan Tanah Jawa Kabupaten Simalungun ini memilki beberapa kesimpulan yaitu:

1. Struktur pasar industri kelapa sawit yang di Kecamatan Tanah Jawa Kabupaten Simalungun merupakan pasar persaingan tidak sempurna yang bersifat oligopoli, besaran rata - rata konsentrasi pasar sebesar 83 persen dengan besaran ini, maka di Kecamatan Tanah Jawa merupakan sifat oligopoli ini dikelompokkan dalam oligopoli ketat dan rata-rata hambatan masuk pasar sebesar 9 persen dengan hal ini maka tidak ada hambatan masuk pasar di Kecamtan Tanah Jawa Kabupaten Simalungun.

2. Perilaku pasar pada industri kelapa sawit di Kecamatan Tanah Jawa Kabupaten Simalungun dapat dilihat dari strategi harga dan strategi produk. Strategi harga dilakukan dengan kolusi antar pelaku pasar yaitu menjadikan biaya produksi tertinggi sebagai pertimbangan harga penjualan. Strategi produk dilakukan dengan cara mengklasifikasikan produk berdasarkan ukuran,harga dan kualitas produk. Kecamatan Tanah Jawa Kabupaten Simalungun menunjukkan terdapat beberapa lembaga pemasaran yaitu petani, agen kecil, agen besar, pabrik. Masing-masing lembaga pemasaran melakukan fungsi-fungsi pemasaran. Pada aktivitas pemasaran adanya ikatan permodalan yang dilakukan petani dengan agen kecil maupun agen besar menyebabkan ikatan kontrak. Di Kecamatan Tanah Jawa mempunyai 3 saluran pemasaran.

3. Analisis kinerja pasar (Market Performance) kelapa sawit di Kecamtan Tanah Jawa Kabupaten Simalungun menunjukan bahwa terdapat 3 saluran pemasaran dengan total marjin yang berbeda-beda. Total marjin yang tertinggi terdapat pada saluran pemasaran III yaitu sebesar 34,06 persen, semakin banyak lembaga pemasaran yang terlibat maka marjin pemasaran semakin tinggi dan farmer share semakin rendah. Saluran pemasaran yang paling efisien adalah saluran pemasaran I (petani-pabrik).

4. Hubungan antara struktur perilaku dan kinerja di Kecamatan Tanah Jawa dapat dilhat dari pendekatan Structure,Conduct, Performance $(S C P)$, Hubungan antara struktur dan perilakuyaitupetani yang menjual tandan buah segar ke agen besar maka struktur pasar oligopoli ketat, dihubungkan dengan perilaku pasar maka petani yang menggunakan saluran pemasaran 2 dan 3 tidak mempunyai kekuatan untuk mengontrol harga, hubungan antara perilaku dan kinerja yaitu saluran pemasaran pendek(saluran 1) memiliki farmer share yang tinggi, hubungan antara struktur dan kinerja yaitu pasar yang digunakan adalah pasar oligopoli ketat maka marjin pemasaran tinggi.

\section{Saran}

Strategi-strategi yang sebainya dilakukan oleh petani untik mengatasi maslah pemasaran yang mereka hadapi yaitu:

1. Melakukan fungsi-fungsi pemasaran untuk meningkatkan nilai tambah dan nilai ekonomis budidaya kelapa sawit dan juga untuk mengatasi ketimpangan peranan antara petani dengan pelaku pasar, sehingga peran petani dapat diperluas tidak saja sebagai produsen. Fungsi pemasaran yang dapat dilakukan oleh petani meliputi fungsi transportasi, pemanenan dan penanganan pasca panen.

2. Petani di Kecamatan Tanah Jawa sebaiknya memilih saluran pemasaran langsung, yaitu saluran pemasaran I. Pada saluran pemasaran tersebut, petani tidak menggunakan lembaga pemasaran, sehingga saluran tersebut lebih efisien, dan lebih menguntungkan.

3. Agar dapat melakukan saluran pemasaran I, maka petani harus memiliki transportasi. Sebaiknya petani bekerjasama untuk mengaktifkan kembali koperasi pertanian serta kelompok tani kelapa sawit dan memiliki transportasi milik bersama, sehingga petani bisa dimudahkan dalam proses pemasaran TBS kelapa sawit secara langsung ke Pabrik Kelapa Sawit dan Diperlukan adanya intervensi pemerintah untuk mengaktifkan kembali koperasi pertanian dengan sistem manajemen dan kinerja yang lebih baik dari sebelumnya.

\section{DAFTAR PUSTAKA}

[BPS] Badan Pusat Statistik. 2015. Statistik Kelapa Sawit Indonesia. Medan.

Dahl DC, Hammond JW. 1977. Market and Price Analysis. Mc. Graw Hill, New York.

Jaya, W.K. 2001. Ekonomi Industri. BPFE, Yogyakarta. 
STRATEGI PEMASARAN KELAPA SAWIT MELALUI PENDEKATAN ANALISIS

Kohls RL, Downey WD. 1972. Marketing of Agricultural Products 4th edition. Macmillan Publishing. New York.
Sinaga et al. 2014. Fluktuasi Harga pada Produk Pertanian. Yogyakarta.

Sitorus, A.S. 2012. Analisis Struktur, Perilaku, Dan Kinerja Industri Kakao Di Indonesia. Departemen Manajemen. Fakultas Ekonomi dan Manajemen. Institut Pertanian Bogor. 